\title{
Relationship between body image and eating disorders: A case study of females between 15-29 years old from Shiraz, Iran
}

Bijan Khajrnoori and Roodabeh Dehghani*

Department of Sociology, Shiraz University, Shiraz, Iran

\section{ABSTRACT}

Research on the etiology, prevention, and treatment of eating disorders has increased over the past 3 decades, but in Iran there is no sociological study about eating disorders. So in this study, eating disorders has been verified from a sociological perspective. Variables such as ICTs use, body-related social comparison, peer and parents' attitudes toward body were examined as the variables that could affect both body image and different types of eating disorders. The study sample was 600 girls and women between 15-29 years old of Shiraz (a city of Iran), were selected through multistage random sampling method. The results showed parents' attitudes toward body, BRSC, and ICTs use can affect both body image (body satisfaction \&t self- discrepancy as the tow components) and eating disorders, on the other hand body image can affect eating disorders. To examine the research model LISREL program was used and the independent variables could explain 63 percent of changes of the dependent variable.

KEY WORDS: BODY IMAGE; BRSC; EATING DISORDERS; PARENTS' ATTITUDES; PEER ATTITUDES; SHIRAZ

\section{INTRODUCTION}

There is general agreement about the criteria for diagnosis of anorexia nervosa (AN) and bulimia nervosa $(\mathrm{BN})$ as defined in the Diagnostic and Statistical Manual of Mental Disorders (DSM IV) (American Psychiatric Association (Nietzel and Wakefield 1994, Fairburn and Harrison (2005). Eating disorders are characterized by severe disturbances in eating behaviors and attitudes. Both AN and BN are characterized by weight preoccupa-

\section{ARTICLE INFORMATION:}

${ }^{*}$ Corresponding Author:

Received $10^{\text {th }}$ March, 2016

Accepted after revision $31^{\text {st }}$ March, 2016

BBRC Print ISSN: 0974-6455

Online ISSN: 2321-4007

Thomson Reuters ISI SCI Indexed Journal

NAAS Journal Score : 3.48

- A Society of Science and Nature Publication, 2016. All rights reserved.

Online Contents Available at: http//www.bbrc.in/ tion, fear of fat and a sense of self unduly influenced by weight and body shape concerns (APA 2000). When distinctions between $\mathrm{AN}$ and $\mathrm{BN}$ are drawn, it is usually because of weight and associated medical complications. People with AN are underweight while people with BN tend to be of average or above-average weight. In addition, the DSM-IV includes fear of becoming fat, and amenorrhea in postmenarchal women as necessary criteria for AN. Less conclusive or agreed upon is the definition and criteria for a diagnosis of Binge Eating 
Disorder (BED). However, people with BED usually suffer from binge eating episodes without the compensatory behaviors seen in BN. There seems to be agreement that eating disorders result in serious physical, psychological, and social difficulties and dysfunction (Russell-Mayhew 2007 and Mervin and Zucker 2010).

Body image is an important aspect of self-representation and self-evaluation during youth and adolescence. Although body image is a multidimensional construct, it is most frequently defined as the degree of satisfaction with one's current physical self (size, shape, general appearance). The importance of body image is evident in its relationship to risk status for eating disorders (Jones 2001).

Many influences have been noted as formative in the development and maintenance of eating-, shape- and weight-related disorders (Thompson et al. 1999, Mervin and Zucker 2010). These factors include, but are not limited to, teasing or critical comments about one's appearance from parents, peers or other significant individuals, early pubertal maturation, sexual abuse, psychiatric disturbance, negative emotionality, poor interoceptive awareness, developmental challenges, academic pressures, and elevated social comparison tendencies (Leon et al. 1995, Levine et al, 1994).

Socio-cultural theory emphasizes on those ideas and beliefs that can be learned through social and cultural factors such as the media, family or history. Stice et al., (2002) stated that the social and cultural effects cause disorders in body image and eating habits.Pressure from parents to lose weight and being ridiculed because of weight or being encouraged because of weight loss are associated with negative body image and eating.

Stice et al., (2002) have also concluded that not only family pressures, but peer pressure also influence body image. Being ridiculed by friends for the weight and pressure of being thinner affects the state of being consent with the body. One of the most important factors related with the developing of ED is the social standard of beauty and thinness that appears in the media (Dittmar et al. 2000). As applied to body image disturbance and eating disorder development, researchers propose that images of models displayed prominently in the media serve as comparison others. When women compare themselves to models in mainstream media, they are evaluating themselves in comparison to a very specific ideal female physique, whereas media is correlated with the internalization of thin- ideal, body dissatisfaction. If women internalize these ideals but do not conform to them, and have friends and family members who do, then they would be in an upward social comparison process, and likely feel body dissatisfaction (Warren 2006).

Studies around the world confirm that a relatively large proportion of teenage girls are encountered with eating disorders. Teens, especially girls, in most cases, pay special attention to their weight and body shape, and often in an attempt to deal with the pressures associated with changes in the critical and challenging period of puberty, adopt wrong eating habits. Therefore, this exposure may cause nutritional behavior problems (Rustaee et al. 2009).

Although exact statistics about the use of weight loss drugs are not available in Iran, according to Hamshahri News Agency reports; Sales of weight loss drugs are high, which itself is indicative of high expenses that people undertake for these drugs. But aside from the negative side effects of these medications, the problem is lack of proper drug effect. Despite the cost of the drugs, the result is not desired. This makes people adopt wrong eating habits, and face anorexia nervosa and bulimia nervosa.

Eating disorders deserve attention for two major reasons (APA 2000). First, the mortality rate for those who do meet the criteria for eating disorders is between 5 and $12 \%$, indicating that eating disorders are indeed some of the most serious mental illnesses. In general, "eating disorders have the highest levels of treatment seeking, inpatient hospitalization, suicide attempts, and mortality of common psychiatric syndromes" (Daniels 2009). In addition, eating pathology increases the risk for future onset of obesity, depressive disorders, anxiety disorders, substance abuse, and health problems (Johnson, et al. 2002,Stice et al. 1999, Stice et al. 2000).

In the meantime, no major sociological research on eating disorders and their relationship with social factors has been done in Shiraz yet. Given the fact that Shiraz is one of the major metropolises in Iran, as well as ethnic and cultural diversity of the city, conducting research on factors related to body image, which can have a significant cultural dimension is important.The questions examined in this study include how much is the frequency of eating disorders among girls and young women? What are the factors affecting eating disorders and what are the direct and indirect impacts of factors affecting eating disorders through body image? Which one is more important and the most effective?

\section{MATERIAL AND METHODS}

This study has been done through survey method. The tools for data collection were self- reported questionnaires. As Zhang et al explain, in self-reported method, respondents have personal place and space to remember their past events (Zhang et al. 2000). In this study bodyrelated social comparison in 15 to 29 years old girls and women of Shiraz was considered as independent variable, body image was considered as the interval variable, and eating disorder as the dependent. 
The total girls and women between 15 to 29 years old of Shiraz are 36237. Based on Lin table, the sample size was 600. The method was multi-stage random sampling. In order to determine the validity and reliability of the questionnaire, the two kinds of content validity and face validity were used. For content validity, the questionnaire was given to some experts and for face validity; it was given to some girls and women between 15 to 29 years old. To measure the reliability of the questionnaire items, Cronbach's alpha technique was used.

\section{INDEPENDENT VARIABLES}

\section{ICT use}

A composite measure of weekly viewing was constructed to account for using ICTs. Participants reported how muchthey watch television during every week, from "not at all" to "very much". These data were weighted and combined to create an average weekly viewing.

\section{BODY-RELATED SOCIAL COMPARISON(BRSC)}

To measure likelihood to engage in comparisons with peers, family members and models, Participants answered the question how often they compare their "overall body" to members of their own sex (e.g., how often do you compare your overall body to that of peers).

\section{PARENTAL ATTITUDES REGARDING BODY}

The parental influence section from the Tripartite Influence Model of Body Dissatisfaction and Eating Disturbances with Adolescent Girls (Berg et al. 2002) with some changes was used to measure perceptions of parental attitudes toward weight and body shape. The index included five statements using a 7-point scalefrom"Strongly disagree" to "Strongly agree." Statements included items like "My mother is on a diet to lose weight" and "My father has made comments or teased me about my appearance".

\section{PEER ATTITUDES REGARDING BODY}

The same questions were used to measure perceptions of peer attitudes toward weight and body shape. The index included five statements using a 7-point scalefrom"Strongly disagree" to"Strongly agree." Statements included items like "My friends are on diet to lose weight" and "My friends have made comments or teased me about my appearance".

\section{BODY IMAGE}

Two measures were used for body image: body areassatisfaction, self-discrepancies for physical characteristics. These measures were used to focus on perceptual aspects of body image (i.e., what people perceive about their bodies such as weight, physical characteristics, and attractiveness).

\section{BODY AREAS SATISFACTION}

A modifed version of Body Areas Satisfaction Scale (Cash 1989) wasused to measure participants' satisfaction, ranging from 1 (very dissatisfied) to5 (verysatisfied), with specific areas of the body such aslower torso (e.g., hips, legs), mid torso (waist, stomach), upper torso (e.g., breasts, arms), muscle tone, weight, and height. Higher scores indicate satisfaction with most areas of the body. The internal consistency of this scale was high in this study $(\alpha=0.93)$.

\section{SELF-DISCREPANCIES FOR PHYSICAL CHARACTERISTICS}

A modified version of The Body-Image Ideals Questionnaire (Cash and Szymanski 1995) was used to measure weighted self-perceived discrepancies (i.e., self-discrepancies from internalized ideals) for multiple physical characteristics. Those physical characteristics include height, muscle tone and definition, body proportions, weight, chest size, and physical coordination. Higher scores indicate greater dissatisfaction with those physical characteristics. The internal consistency revealed good reliability of this scale $(\alpha=0.92)$.

\section{EATING DISORDERS}

Eating disorder symptoms has been measured by the Eating Disorder Diagnostic Scale (EDDS) in this study. The EDDS consists of a diagnostic scale and a symptom composite scale. The diagnostic scale can be used to diagnose AN, BN and BED. The symptom composite score indicates participants' overall level of eating pathology. The EDDS (Stice et al. 2000) contains items assessing the DSM-IV diagnostic criteria for anorexia nervosa, bulimia nervosa, and binge eating disorder. Responses can be used to generate DSM-IV diagnoses for the three eating disorders. Items can also be standardized (to control for the different response formats) and summed (except the height and birth control pill use items) to create an overall eating disorder symptom composite (Stice et al. 2004). The preliminary psychometric study (Stice et al., 2000) provided evidence that the EDDS was reliable and valid within a sample containing both adolescents and adults. The eating disorder symptom composite in this study had an alpha of 0.88 .

\section{HYPOTHESES}

1. There is relationship between body-related social comparison and eating disorder. 
2. There is relationship between family attitudes toward body and eating disorder.

3. There is relationship between friends' attitudes toward body and eating disorder.

4. There is relationship between body satisfaction and eating disorder.

5. There is relationship between self-discrepancy and eating disorder.

6. There is relationship between ICT use and social comparison.

\section{RESULTS AND DISCUSSION}

We used the EDDS to assess AN, BN and BED. Because most patients with eating disorders do not fulfill a full syndrome diagnosis (Fairburn \&t Harrison 2003), we decided to include both full and sub threshold EDDS diagnoses of $\mathrm{AN}, \mathrm{BN}$ and $\mathrm{BED}$, similar to (Sticeet al.2004). Sub threshold diagnoses required the presence of all of the symptoms of the disorder, but the severity

\begin{tabular}{|c|c|c|}
\hline & $\mathrm{N}$ & Percent \\
\hline Sub threshold Anorexia & 37 & 6.1 \\
\hline Full threshold Anorexia & 58 & 9.6 \\
\hline Total (Anorexia) & 95 & 15.7 \\
\hline Sub threshold Bulimia & 93 & 15.4 \\
\hline Full threshold Bulimia & 14 & 2.3 \\
\hline Total (Bulimia) & 107 & 17.7 \\
\hline Sub threshold Bing Eating & 25 & 4.2 \\
\hline Full threshold Bing Eating & 35 & 5.8 \\
\hline Total (Bing Eating) & 60 & 10 \\
\hline Total & 262 & 43.4 \\
\hline
\end{tabular}

of one of these symptoms was of sub diagnostic severity (e.g. binge eating only once per 2 weeks or having a body mass index of less than 18.5). Based on the EDDS, the sample $(\mathrm{N}=602)$ included 95persons with $\mathrm{AN}, 107$ persons with $\mathrm{BN}$, and 60 persons with BED.

According to Table 2, the following statements can be stated:

1. There is a positive correlation between the use of information and communication technologies (ICTs) and body- related social comparison. The use of ICT makes the person involved in the process of social comparison, with models that are observed in the media and with friends, peers and family members.

2. There is a negative correlation between body- related social comparison and body satisfaction. In fact, we can say that with increasing social comparison, body satisfaction will be reduced. According to the theory of social comparison, we can say that the people involved in the media images are comparing their bodies with a perfect body. Also, according to this theory, we can say that when people do not match to these images, and they find friends and people around them are matched to those images, then they may face upward social comparison and as a result, experience body dissatisfaction.

3. There is a positive correlation between self-discrepancies and body- related social comparison. One can provide an explanation as above for discrepancies.

4. There is a positive correlation between body- related social comparison and eating disorders. by increasing social comparison among individuals, eating disorders increase.

5. There is a negative correlation between attitude of parents towards the body and body satisfaction. It

Table 2: Correlations, Means and Standard Deviations of Variables $(\mathrm{N}=602)$.

\begin{tabular}{|c|c|c|c|c|c|c|c|}
\hline & $\begin{array}{l}\text { ICTs } \\
\text { use by } \\
\text { responder }\end{array}$ & $\begin{array}{l}\text { body } \\
\text { comparison }\end{array}$ & $\begin{array}{l}\text { family } \\
\text { attitudes } \\
\text { toward body }\end{array}$ & $\begin{array}{l}\text { friends } \\
\text { attitudes } \\
\text { toward body }\end{array}$ & $\begin{array}{l}\text { body } \\
\text { satisfaction }\end{array}$ & self-discrepancy & $\begin{array}{l}\text { eating } \\
\text { disorders }\end{array}$ \\
\hline 1 & 1 & $0.25^{* *}$ & 0.08 & 0.07 & 0.06 & $-0.13^{* * *}$ & $0.1^{*}$ \\
\hline 2 & & 1 & $0.1^{*}$ & $0.16^{* * *}$ & $-0.12^{* *}$ & $0.1^{*}$ & $0.23^{* * *}$ \\
\hline 3 & & & 1 & $.0 .76^{* *}$ & $-0.11^{* *}$ & 0.08 & $0.49^{* * *}$ \\
\hline 4 & & & & 1 & $-0.2^{* * *}$ & $0.26^{*}$ & $0.58^{* *}$ \\
\hline 5 & & & & & 1 & $-0.75^{* * *}$ & $-0.13^{* * *}$ \\
\hline 6 & & & & & & 1 & $0.09^{*}$ \\
\hline 7 & & & & & & & 1 \\
\hline M & 15.09 & 4.55 & 1.33 & 1.71 & 17.77 & 19.56 & 0 \\
\hline SD & 6.81 & 2.78 & 2.44 & 2.72 & 7.22 & 6.67 & 11.34 \\
\hline
\end{tabular}




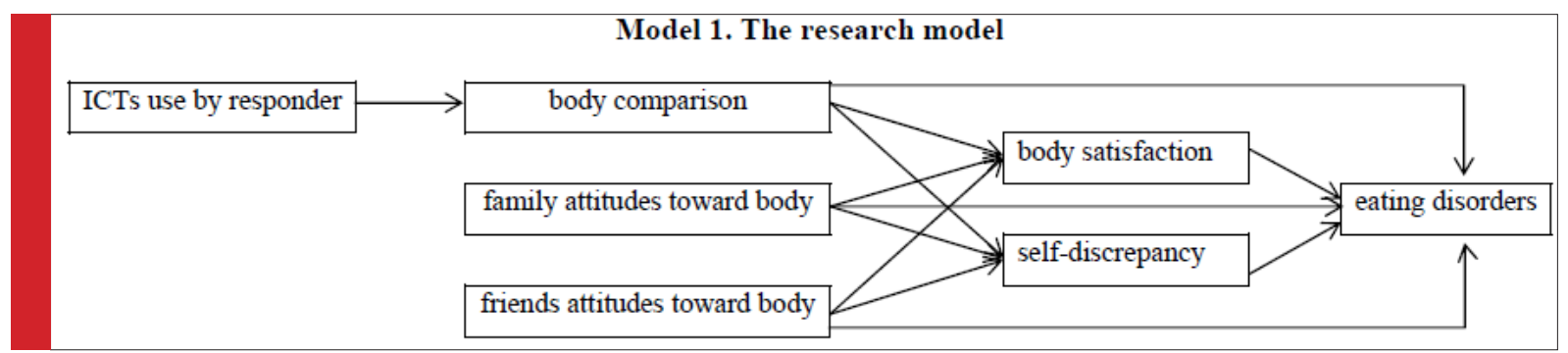

can be said that with the increasing negative attitude of parents towards the body, dissatisfaction with their body increases.

6. There is no correlation between parent attitudes toward the body and self-discrepancies. When there is a negative attitude of parents towards the child's body, it cannot be said that there will be difference between their body and ideal body in their mind.

7. There is a positive correlation between parental attitudes toward the body and eating disorders. With the increase in parent negative attitudes toward a person's body, the rate of eating disorders increases.

8. There is a negative correlation between friends' attitude towards the body and body satisfaction. Friends with negative attitudes towards the body, reduce body satisfaction. The attitude of friends toward the body, affects one's attitude toward his/ her body.

9. There is a positive correlation between friends' attitude towards the body and self-discrepancies. When a friend's attitude toward the child's body is negative, it can be said that a gap will be created between the ideal body in mind and the body.

10. There is a positive correlation between friends' attitude towards the body and eating disorders. In fact, it can be said that by increasing the friends' negative attitude towards body, the possibility of eating disorders in the person increases.The path analysis was studied using LISREL software

By investigating the direct and indirect relationship between independent variables and the dependent variable, Model 1 was tested as a research model in the software LISREL. Model 2, is the model that LISREL software proposed as the fitted model. According to Model 2, it can be said that social comparison variables related to body, parental attitudes toward the body, body satisfaction and self-discrepancies have an impact on eating disorders. The overall research model could explain 61 percent of the dependent variable changes. Fitness indicators of the models are stated below.

Research on the etiology, prevention, and treatment of eating disorders has increased dramatically over the past 3 decades, but in Iran there is no sociological study about eating disorders. On the other hand a large sample of subjects was studied, to realize the prevalence of the disease among the population. This study sought to examine the relationship of factors such as the use of ICT and social comparison, the attitude toward the body and the components of body image with eating disorders. The results showed that there is a relation between the use of ICTs and BRSC. People, who use ICTs more, particularly compare their body more than others do. In addition, BRSC is associated with body image components and eating disorders associated. People who are more involved in BRSC, have less body satisfaction, as

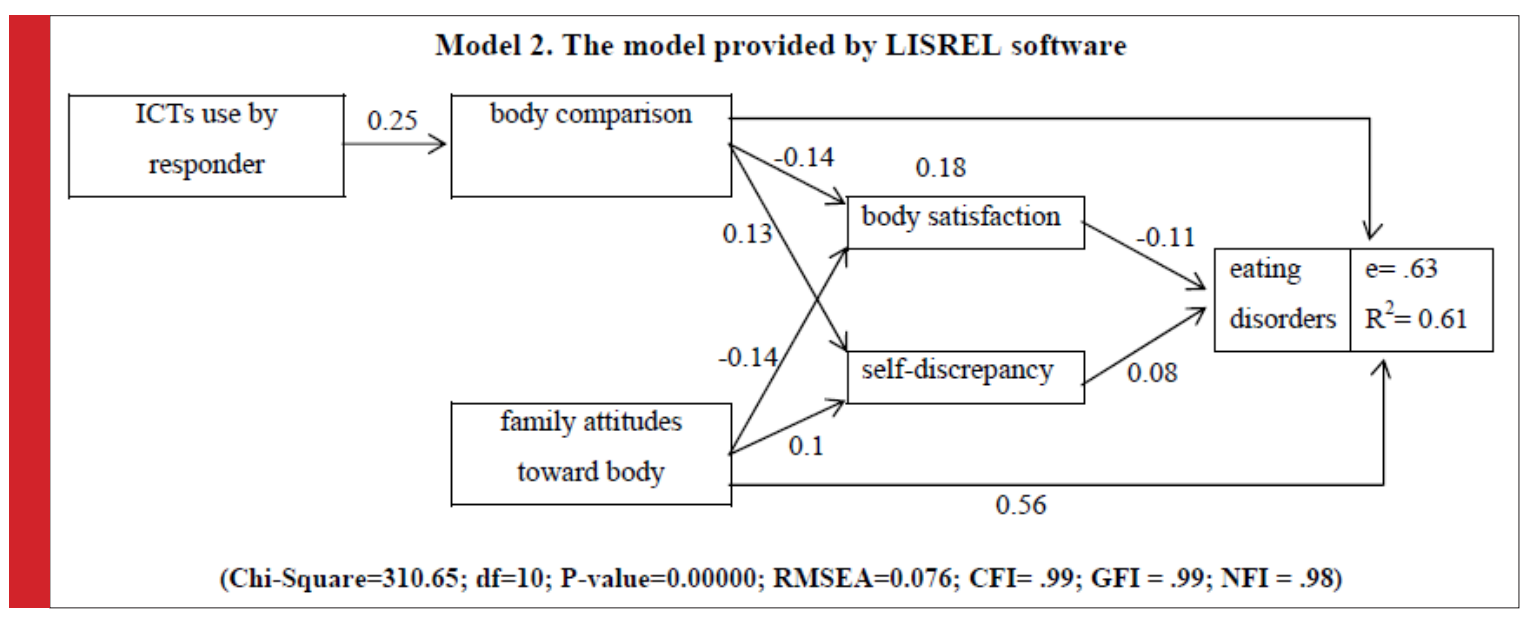


well as the great difference between their physical body and their ideal.

On the other hand, dissatisfaction with body and selfdiscrepancy both affect eating disorders. When body dissatisfaction and self-discrepancy increases, more symptoms of eating disorders escalate. BRSC is also associated with components of body image, and an increase in BRSC can exacerbate eating disorders. Another result of model 2 is that there is a relation between attitude of family members to the body and component of body image. That means the more negative parental attitudes toward body, the lower body satisfaction and self-discrepancies. In addition, the parents' attitudes towards body have the strongest effect on eating disorders among all the variables. Therefore, we can see how others' attitudes and behaviors can affect people's eating habits. Due to the importance of the issue and its relationship to physical and mental health of individuals, debates on the body and eating disorders and paying attention to the risky factors are very important. So in light of these cases, we need to look at factors associated with them. In these cases, according to the results of this study, it can be said that, parents and their attitude toward the body should be a priority, since it has the greatest effect on eating disorders. In this regard, it is essential that attention be given to the media. The media affects body image components and eating disorders indirectly through BRSC, which should be considered.

\section{REFERENCES}

American Psychiatric Association (2000) Practice guideline for the treatment of patients with eating disorders (revision). Supplement to the American Journal of Psychiatry 157(1):1-39.

Berg, P J.K. Thompson, K. Obremski-Brandon and M. Coovert (2002). The tripartite Influence model of body image and eating disturbance: A covariance structure modeling investigation testing the mediational role of appearance comparison, Journal of Psychometric Research 53(5):1007-1020.

Cash T F andM. L. Szymanski (1995). The development and validation of the Body-Image Ideals Questionnaire, Journal of personality assessment 64 (3): 466-477.

Cash T F(1989).Body-image affect: Gestalt versussummingthe parts. Perceptual and Motor Skills, 69, 17-18.

Daniels KA (2009). Attitudes toward Eating Disorders and the Role of Body Dissatisfaction in College Women. A Thesis Presented To The Faculty of the Department of Psychology.

Dittmar,H B. Lloyd,S. Dugan,Halliwell E., Jacobs N. and Cramer H. (2000). The Body Beautiful, English Adolescents Images of Ideal Bodies, Sex Roles 42:887-915.

Fairburn C.G.and Harrison P. J. (2003).Eating disorders. Lancet 361: 407-416.

Johnson,JG P.Cohen, S. Kasen and J. S. Brook (2002).Eating disorders during adolescence and the risk for physical and mental disorders during early adulthood Archives of General Psychiatry 59: 545-552.

Jones DC(2001). Social comparison and body image: attractiveness comparisons to models and peers among adolescent girls and boys, Sex Roles, Vol. 45, Nos. 9/10. pp. 645-664.

Leon, GR., J.A. Fulkerson, C. L.Perry and M.B. Early-Zald(1995). Prospective analysis of personality and behavioral vulnerabilities and gender influences in the later development of disordered eating. Journal of Abnormal Psychology 104(1):140.

Levine MP ,L.Smolak,A. F.Moodey,M. D. Shuman and L.D. Hessen (1994).Normative developmental challenges and dieting and eating disturbances in middle school girls, International Journal of Eating Disorders 15:11-20.

Mervin RM and N. L. Zucker (2010) Interoceptive awareness in eating disorders: Distinguishing lack of clarity from nonacceptance of internal experience, Cognition and Emotion 24(5): 892-902.

Nietzel MT and J. C. Wakefield (1996).American Psychiatric Association Diagnostic and Statistical Manual of Mental Disorders. Contemporary Psychology 41: 642-651.

Russell-Mayhew (2007). Eating Disorders and Obesity as Social Justice Issues: Implications for Research and Practice, Journal for Social Action in Counseling and Psychology 1(1):1-13.

Rustaee,R M. H.Faraji, M.Dejkam, A.Hushyar Rad, Y.Mehrabi and T. Zoghi (2009). studying the prevalence and factors associated with eating disorders of high school girls students in Tehran in 1388, International Journal of Eating and Food Industry, eighth year, No. 1, pp. 144-135.

Stice E., R.Cameron, J. D.Killen, C.Hayward and C.B. Taylor (1999). Naturalistic weight reduction efforts prospectively predict growth in relative weight and onset of obesity among female adolescents. Journal of Consulting and Clinical Psychology 67: 967-974.

Stice E., C.Hayward, R.Cameron, J. D.Killen, and C. B. Taylor (2000). Body image and eating related factors predict onset of depression in female adolescents: A longitudinal study". Journal of Abnormal Psychology 109: 438-444.

Stice E, M.Fisher \&t E.Martinez (2004). Eating disorder diagnostic scale: additional evidence of reliability and validity, Psychological Assessment 16(1): 60-71.

Stice E., C.F. Telch \&t S. L. Rizvi (2000). Development and validation of the Eating Disorder Diagnostic Scale: a brief selfreport measure of anorexia, bulimia, and binge-eating disorder, Psychological Assessment 12(2):123.

Thompson, JK L.J.Heinberg, M. N. Altabe and S.Tantleff-Dunn (1999). Exacting beauty: Theory, assessment and treatment of body image disturbance. Washington DC: American Psychological Association.

Warren CS(2006). Social comparison, ethnicity, body image, and media exposure to thin-ideal models: an experimental study (Doctoral dissertation, Texas A\&tM University).

Zhang, S., T. Benson and X.Deng (2000). A Test-Retest Reliability Assessment of the International Self-Report Delinquency Instrument. Journal of Criminal Justice 28: 283-295. 